\title{
POST INSTRUMENTAL INCOMPLETE UTERINE RUPTURE WITH LEFT OVARIAN CYST A RARE CASE
}

Vijayalakshmi B ${ }^{1}$, Divya Kannari²

\section{HOW TO CITE THIS ARTICLE:}

Vijayalakshmi B, Divya Kannari. "Post Instrumental Incomplete Uterine Rupture with Left Ovarian CYST a Rare Case". Journal of Evolution of Medical and Dental Sciences 2015; Vol. 4, Issue 63, August 06; Page: 11090-11093, DOI: $10.14260 /$ jemds/2015/1598

ABSTRACT: INTRODUCTION: Uterine rupture stands as a single obstetric accident during pregnancy and child birth, and one of the leading causes for maternal and fetal morbidity and mortality. Although there is decline in different studies, it is a potentially catastrophic event in which the integrity of myometrial wall is breeched.(1) Survivors are often encumbered with morbidities such as impaired reproductive function as a result of surgical management leading to marital disharmony and psychological trauma.(2) The incidence of uterine rupture can be dropped with good antenatal care, access to skilled delivery and emergency obstetric care, emergency transport system, equitable distribution of health staff and availability of blood banks with sustainable blood supply. Uterine rupture usually occurs during delivery due to misuse of oxytocics, obstetrical procedure like forceps/vacuum which are applied without fulfillment of criteria for application and inadequate skills. We here by present a case report of post instrumental incomplete uterine rupture.

KEYWORDS: Uterine rupture, Post-partum hemorrhage, Instrumental delivery, Scarred and unscarred uterus.

CASE REPORT: P3L3 delivered a male baby of weighing 3.5kg at 11AM by forceps application for prolonged second stage of labor in a government hospital and she was referred to our hospital at 5:30PM with history of post-partum hemorrhage (PPH) with 1 pint of packed cells on flow there was delay of about $5 \frac{1}{2}$ hours to reach our hospital after delivery. On general examination patient was in shock with pulse rate $120 / \mathrm{min}, \mathrm{BP}-90 / 60 \mathrm{mmHg}, \mathrm{P} / \mathrm{A}$-uterus was contracted and retracted. P/S examination a sutured episiotomy wound seen with vaginal lacerations along with active bleeding from posterior fornix, cervical os was intact. Patient was diagnosed as P3L3 with immediate post natal day with traumatic PPH due to forceps application.

Her investigations revealed $\mathrm{Hb}-6 \mathrm{gm} \%$, blood group 0 positive, platelet count- 2.61 lakhs/cmm, coagulation profile within normal limits. Patient was immediately posted for exploration \& suturing in OT after arranging adequate blood \& packed cells, \& FFPs. Under general anesthesia vaginal suturing done but bleeding continued.

After thorough Re-examining a tear in the posterior fornix noted which was communicating into the pouch of Douglas. Then immediate decision for laparotomy was taken. Intraoperative findings revealed uterus to be well contracted and retracted, along with a huge solid left ovarian cyst of about $10^{*} 10 \mathrm{cms}$ (Fig. no. 1) along with incomplete uterine rupture at the level of lower uterine segment on left side along with the broad ligament hematoma. The peritoneum was intact with the myometrial rupture. The peritoneum picked up, separated and pushed down along with the bladder. Then total peripartum hysterectomy along with cystectomy on left side done. Intraoperatively 2 pints of whole blood \& 2 pints of FFP were transfused. Postoperative period was uneventful. After removal of sutures on $8^{\text {th }}$ post-operative day patient was discharged. 


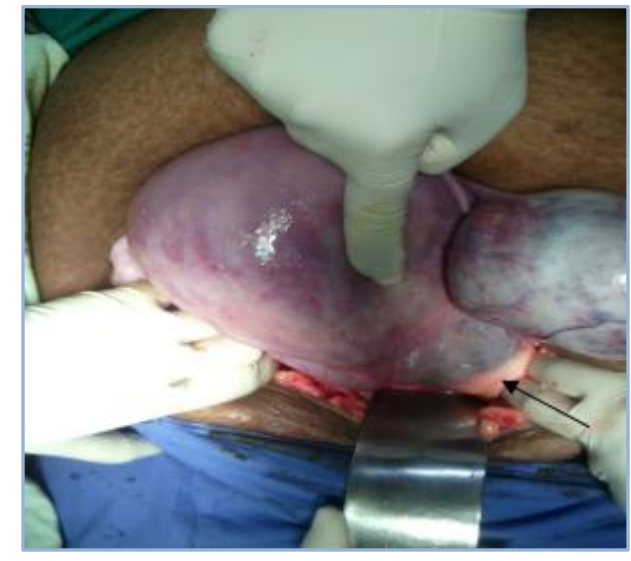

Fig. 1: Incomplete Ruptre of Uterus

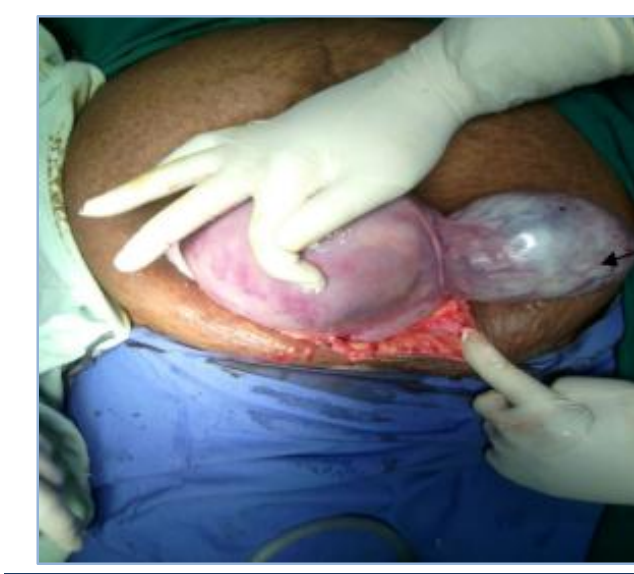

Fig. 2: Left Ovarian Mass Leading to prolonged second stage

DISCUSSIONS: The status of forceps delivery is constantly under discussion within the specialty and with pediatrics colleague. Even though there are lots of controversies, efforts are made for improvement in application of this instrument in the interest of mother and the baby which is life saving and rewarding experience when applied properly.(3) So we can say that forceps application after fulfillment of criteria's in an expert hand is an art but not a dangerous instrument in a skilled obstetrician. There are varieties of forceps available but high forceps, mid cavity and rotational forceps has no role in modern obstetrics.(4) Now a day an outlet forceps only should only be applied after maternal verbal consent.

\section{Uterine Rupture is one of the most common Obstetrics Emergencies threatening the lives of both Mother and Fetus. There are two types of Uterine Rupture:}

1. Complete - were the whole thickness of uterine wall is involved, usually occurring in an Unscarred uterus.

2. Incomplete, where the visceral peritoneum remains intact as seen in scar dehiscence.

In our case it was an incomplete rupture in a un scarred uterus at the level of lower uterine segment with intact peritoneum. Ovarian cyst may be the region for prolonged second stage and forceps application.

The risk factors for uterine rupture include obstructed labor, grand multiparty, previous scarred uterus, uterine anomalies, inappropriate prostaglandin and oxytocin usage, previous instrumental abortions, vacuum extraction and forceps delivery.

The necessary requirements for forceps application are that the fulfillment of criteria and after confirming proper application, traction should be applied during contraction with prior episiotomy.

The amount of traction should be least necessary to accomplish safe fetal head descent. In biomechanical studies, safe limit of 45 founds in primi Para \& 30 pounds in multi Para have been suggested. Though there is no consensus on the amount of traction force, (5) the angle of traction is important so to ensuring that everything has been done accordingly to proper protocols, if no progress is observed in three traction, an attempt to abdominal delivery should be considered. After all forceps deliveries a thorough examination of both mother and the new born is mandatory. 
The maternal complications like perinial tear vaginal tear cervical tear, extension of episiotomy, traumatic PPH, urinary and fecal in continence, and the fetal complications like impression mark, abrasions on the face, cephalohematoma, skull fracture, and cerebral palsy can occur.

In our case it was an incomplete rupture in a un scarred uterus at the level of lower uterine segment with intact peritoneum. Ovarian cyst may be the region for prolonged second stage and forceps application.

CONCLUSION: We can conclude that obstetrics' forceps has a significant place in obstetrics'. As it is a lifesaving procedure for mother and fetus in many situation.in skilled hand it is very safe and important to cut short of second stage of labor or even prophylactic use also. Successful result can be achieved more only by skill and not by force.

Sound clinical evaluation and adherence to the ground rule and skill of operator will minimize the risk of failure and complication. Using outlet forceps the overall rates of maternal and perinatal morbidity and mortality are negligible and even comparable to spontaneous vaginal delivery.

Over the years cesarean delivery rate has increased while instrumental delivery date has fallen dramatically over past decade. ACOG 2011 recommends forceps delivery has on acceptable and safe option for delivery. Outlet forceps plays a very important role in obstetrics practice and remain appropriate tools in the armamentarium of the modern obstetrics, so in modern obstetrics outlet forceps is having a definite role.

All the young obstretitician must have knowledge and confidence in applying the instrumental vaginal deliveries. Even nowadays government of India in Emoc training for medical officer in service (MBBS) included the forceps and vacuum delivery in the syllabus to teach them, so they can help the nation in decreasing the maternal mortality rate.

\section{REFERENCES:}

1. Dennen PC. Dennen \& \#8217; s Forceps Deliveries 3rd ed, Davis Company, F. A, New York, 1989; 188.

2. American College of Obstetrics and Gynecology. Operative vaginal delivery. Clinical management guidelines for obstetrician-gynecologists. American College of Obstetrics and Gynecology. Int J Gynaecol Obstet. 2001; 74(1): 69-76. [Pubmed]

3. Johnson JH, Figueroa R, Garry D, Elimian A, Maulik D. Immediate maternal and neonatal effects of forceps and vacuum-assisted deliveries. Obstet Gynecol. 2004; 103(3):513-8. http://dx.doi.org/10.1097/01.A0G.0000114985.22844.6d [Pubmed]

4. ACOG Medical Teaching /Module 2011 forceps incidence in modern Era.

5. Yancey MK, Herpolsheimer A, Jordan GD, Benson WL, Brady K. Maternal and neonatal effects of outlet forceps delivery compared with spontaneous vaginal delivery in term pregnancies. Obstet Gynecol. 1991; 78(4):646-50. [Pubmed] 


\section{AUTHORS:}

1. Vijayalakshmi B.

2. Divya Kannari

\section{PARTICULARS OF CONTRIBUTORS:}

1. Associate Professor, Department of Obstetrics and Gynaecology, Vijayanagara Institute of Medical Sciences.

2. Resident, Department of Obstetrics and Gynaecology, Vijayanagara Institute of Medical Sciences.

FINANCIAL OR OTHER

COMPETING INTERESTS: None

\section{NAME ADDRESS EMAIL ID OF THE CORRESPONDING AUTHOR:}

Dr. Vijayalakshmi B,

H. No: 10/2, Ward No. 19,

Behind Government School,

Patel Nagar, Ballari-583101.

E-mail: vijaya.b.yadav72@gmail.com

Date of Submission: 21/04/2015.

Date of Peer Review: 22/04/2015.

Date of Acceptance: 23/07/2015.

Date of Publishing: 06/08/2015. 